MOBILIZATION OF COLLOIDS IN GROUNDWATER DUE TO INFILTRATION OF WATER AT A COAL ASH DISPOSAL SITE

P.M. Gschwend, D.A. Backhus, J.K. MacFarlane, and A.L. Page

MIT-EL 88-004

September 1988 


\title{
MOBILIZATION OF COLLOIDS IN GROUNDWATER DUE TO INFILTRATION OF WATER AT A COAL ASH DISPOSAL SITE
}

\author{
PHILIP M. GSCHWEND", DEBERA A. BACKHUS", JOHN K. MacFARLANE and \\ A.L. PAGE \\ ${ }^{-}$R.M. Parsons Laboratory for Water Resources and Hydrodynamics, Department of Civil \\ Engineering, Massachusetts Institute of Technology, Cambridge, MA 02139 (U.S.A.) \\ ${ }^{b}$ Department of Soil and Environmental Science, University of California, Riverside, Riverside, \\ CA 92521 (U.S.A.)
}

(Received January 17, 1990; accepted for publication August 14, 1990)

\section{ABSTRACT}

Gschwend, P.M., Backhus, D.A., MacFarlane, J.K. and Page, A.L., 1990. Mobilization of colloids in groundwater due to infiltration of water at a coal ash disposal site. J. Contam. Hydrol., 6: 307-320.

We investigated groundwaters in the vicinity of a coal ash site near an electric generating station in the western U.S.A. The purpose of the study was to ascertain why fine particles or colloids appear in some subsurface water samples there. If such fine particles are merely introduced during bailing or pumping operations which suspend otherwise immobile soil colloids, we should exclude these particulate materials from the water samples before analysis intended to quantify what is moving through the aquifer. However, if the colloids were truly suspended and moving with the groundwater flow in situ, then we should include their contribution to our assessment of the mobile loads.

Application of very careful sampling techniques (slow pumping rates, no atmoepheric exposure) did not cause the large quantities of colloids obeerved previously to disappear from well water in which they occurred. Additionally, the same sampling procedures did not cause similar abundances of colloids to appear in waters collected from neighboring wells installed and developed in the same manner and in the same geologic strata. Thus we believe sampling artifacts do not explain the colloids' presence in the groundwater samples.

On the other hand, the groundwater chemistry and the nature of the suspended colloids (size, composition) strongly suggest these fine particles were suspended and therefore moving with the groundwater flow. At wells exhibiting large amounts of suspended colloids $\left(\sim 10-100 \mathrm{mg} \mathrm{L}^{-1}\right)$, the water was enriched in $\mathrm{CO}_{2}$ and depleted in $\mathrm{O}_{2}$ relative to nearby locations. The colloids were typically between 0.1 and $2 \mu \mathrm{m}$ in size and were primarily silicates. These results suggest to us that, where infiltrating water is percolating through a site that has been mixed with coal ash, the secondary carbonate minerals in the soils are being dissolved; removal of this cementing carbonate phase may consequently release soil silicate colloids to be carried in the flowing water.

Such processes may enhance contaminant transport in groundwater by augmenting the pollutant load moving in the groundwater, and increasing the permeability of the porous medium to pollutant infiltration with waste water and/or rainwater. 
It is now recognized that some of the suspended solids observed in ground. water samples may be moving through the subsurface (Champ et al., 1984; McDowell-Boyer et al., 1986; Gschwend and Reynolds, 1987; Buddemeier and Hunt, 1988; Ryan, 1988). In particular, the colloidal fraction, spanning microparticles of $\sim 1 \mu \mathrm{m}$ size down to macromolecules of $\sim 1$ - $\mathrm{nm}$ dimension, appear susceptible to transport through porous media, since they are too small to be physically trapped by the openings between soil grains and to experience settling in excess of their Brownian motions. To the extent that chemicals of interest (e.g., low-solubility organic pollutants like polycyclic aromatic hydrocarbons, polychlorinated biphenyls, or polychlorinated dibenzodioxins or highly particle-reactive inorganic substances like trace metals and certain radionuclides) become associated with these mobilized colloids, the transport of these substances in groundwater will be "facilitated" over that due to dissolved species transport alone (Champ et al., 1984; Enfield and Bengtsson, 1988).

Unfortunately, traditional groundwater sampling methods appear to introduce large quantities of particles into the water which were not actually suspended in situ. Consequently, until now light scattering materials in groundwater samples have been presumed to come primarily from sampling artifacts. Thus the role of colloids as mediators of chemical transport through the subsurface has been generally ignored.

We have pursued the development of a sampling protocol which allows us to collect groundwater samples containing only those colloidal materials actually present and suspended in situ (Backhus et al., 1986; Ryan, 1988). Notably, this procedure pumps water from the ground at a very low flowrate for an extended period (hours), thereby thoroughly flushing the well while not subjecting the adjacent aquifer solids to greatly increased pumping-induced shear stresses. Additionally, contact of the water with the atmosphere is avoided so that $\mathrm{O}_{2}$ and $\mathrm{CO}_{2}$ exchanges are minimized. Using these procedures, we believe most colloidal materials observed in our samples are suspended, and therefore mobile, in the subsurface.

This study was initiated to discern whether colloids in groundwater seen previously near a coal ash disposal site were actually suspended in situ or were a result of sampling procedures.

The study site

The site is located in the southwestern U.S.A. in the vicinity of a coal-fired electric power plant. The local geology is dominated by sand and gravel alluvium. X-ray diffraction analysis of the $<125-\mu \mathrm{m}$ fines fraction obtained from road-cut samples revealed primarily quartz $(\sim 80 \%)$, calcite $(\sim 20 \%)$, and a few percent dolomite. Aluminosilicate clays and gypsum were not detected in 
these samples, although thin discontinuous clay layers have been observed in soil cores from the site. The phreatic aquifer beneath the site lies $20-60 \mathrm{~m}$ below the highly irregular ground surface, and high-conductivity paleochannels of a nearby river run beneath the site in a northeast to southwest direction. Regional groundwater flow is to the south at a rate of only $30-60 \mathrm{~cm} \mathrm{yr}^{-1}$ (Fig. 1). The area receives only $10-15 \mathrm{~cm}$ of annual rain, and the vegetation is sparse desert scrub.

Ashes from coal combustion are buried in a topographical depression. The ashes are prevented from washing away during infrequent rains by a dam on the southerly end of the ash landfilling area. This damming also has caused focussed infiltration and leaching of the ashes by rain. In an effort to minimize the off-site transport of the resulting salty groundwaters, high-volume interceptor wells are used to extract contaminated groundwater. Thus at times, the flows near these interceptor wells deviate greatly from the regional flow direction and must be substantially increased over ambient rates. An area of relatively high electrical conductivity in the groundwater has been found near the ash disposal site (Fig. 1).

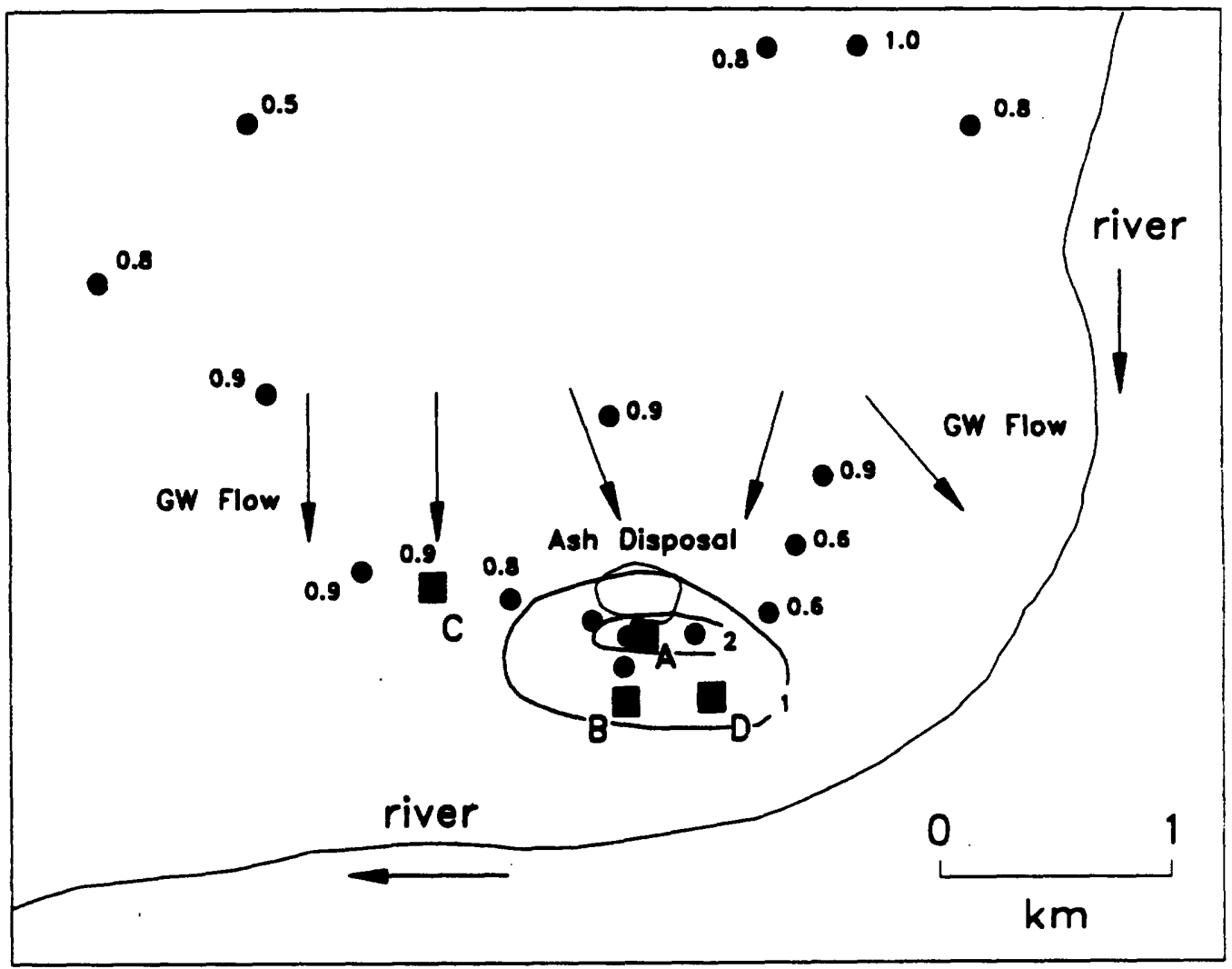

Fig. 1. Well locations and general directions of groundwater flow. Also shown are electrical conductivities $\left(\mathrm{mS} \mathrm{cm}^{-1}\right)$ in groundwater which reveal a salty plume near the ash disposal area. 
METHODS

\section{Sampling}

Groundwater samples were collected at two wells, $A$ and $B$ (see Fig. 1), in April 1986 and again at wells $A, B, C$ and $D$ in August 1987. Well $C$ was installed in January 1983, while wells $A, B$ and $D$ were drilled in October 1985 , using conventional bentonite mud rotary drilling ( $\frac{5}{8}$ in or $19-\mathrm{cm}$ diameter). Two-inch $(5 \mathrm{~cm})$ PVC (polyvinyl chloride) monitoring wells with 0.020 -in $(0.5 \mathrm{~mm})$ screen slots were used, and their screened intervals were packed with $\frac{1}{8}-\frac{1}{4}$ in $(0.32-0.64 \mathrm{~cm})$ pea gravel. All wells were developed using compressed air.

Groundwater was withdrawn using a Fultz ${ }^{\circledR}$ positive displacement gear pump (Fultz Inc., Lewistown, Pennsylvania, U.S.A.), modified by us to operate at low $\left(100 \mathrm{~mL} \mathrm{~min}^{-1}\right)$ flow rates. Groundwater was pumped to the surface through polypropylene tubing and was directed through a Plexiglas ${ }^{\circledR}$ cell in which $\mathrm{pH}, E_{\mathrm{H}}$ (platinum), electrical conductivity and dissolved oxygen electrodes were present. Electrodes were calibrated using solutions of known composition at the ambient groundwater temperature. Samples were collected after these water quality parameters stabilized, usually more than an hour after pumping was initiated. Groundwater samples were carefully collected in glass dissolved-oxygen (DO) bottles by filling from the bottom and displacing at least two bottle volumes. In our study, we chose to use glass bottles without headspace rather than plastic vessels for colloids because we believe negatively charged glass surfaces would inhibit colloidal losses to the walls and the absence of headspace would prevent solution changes due to loss of $\mathrm{CO}_{2}$ or gain of $\mathrm{O}_{2}$. Several major ion constituents were also analyzed in these samples, and our data compare well with the results on groundwater stored in plastic bottles. Groundwater was also drawn directly from the pumped stream into 5-mL plastic syringes. The syringes were subsequently fitted with $25-\mathrm{mm}$ Swinnex filter holders (Millipore, Bedford, Massachusetts, U.S.A.) containing 0.03- $\mu \mathrm{m}$ Nuclepore $^{\circledR}$ filters (Pleasanton, California, U.S.A.), and the water was forced through the membrane filters by application of a steady constant pressure to the syringe plungers. In the April 1986 sampling we failed to rinse the filters with distilled water, and consequently large precipitates of sodium chloride (and possibly $\mathrm{CaCO}_{3}$ ) crystals formed on drying and obscured subsequent microscopic and elemental analyses. Thus, for the August 1987 samples, we forced $5 \mathrm{~mL}$ of distilled water through the Nuclepore ${ }^{\circledR}$ filters after collecting groundwater colloids on them. These filters were subsequently dried in Petri dishes in a desiccator.

Analysis

Upon returning to the laboratory, the water samples and filters were investigated in a variety of manners to quantify and characterize their colloidal constituents. First, within 5 days of sample collection, laser light scattering 
(LLS) analyses were performed on groundwater suspensions to assess the relative abundance of scatterers and to ascertain colloid sizes. A Coulter ${ }^{\circledR}$ N4 Submicron Particle Analyzer (Hialeah, Florida, U.S.A.) was used with light of $633 \mathrm{~nm}$ supplied by a $\mathrm{He}-\mathrm{Ne}$ laser and scattered light detection at $90^{\circ}$. Generally, the colloidal populations were so polydispersive as to preclude reproducible sizing by photon correlation spectroscopy. Scanning electron microscopy (SEM) and scanning electron microscopy-energy dispersive X-ray analyses (SEM-EDAX) were performed on colloids recovered on our field filters. Finally, the major cations, $\mathrm{Ca}^{2+}, \mathrm{Mg}^{2+}$ and $\mathrm{Na}^{+}$, were analyzed in acidified groundwater samples using a Perkin-Elmer ${ }^{\circledR}$ atomic absorption spectrophotometer; major anions, $\mathrm{Cl}^{-}$and $\mathrm{SO}_{4}^{2-}$, were determined using a Dionex ${ }^{\circledR}$ ion chromatograph; and alkalinity was assessed by titration with standardized hydrochloric acid titrant and identification of the equivalence point by use of the Gran function.

\section{RESULTS AND DISCUSSION}

\section{Sampling artifacts}

As a prerequisite to all other exploration, we began our studies on the groundwater in April 1986 by examining the effects of pumping rate on the colloids observed. We focused on two wells, $A$ and $B$, located near an area impacted by coal ash disposal. Turbidity had been noted in the past at well $A$ but not well $B$. Fig. 2 shows the LLS intensity we observed at these wells

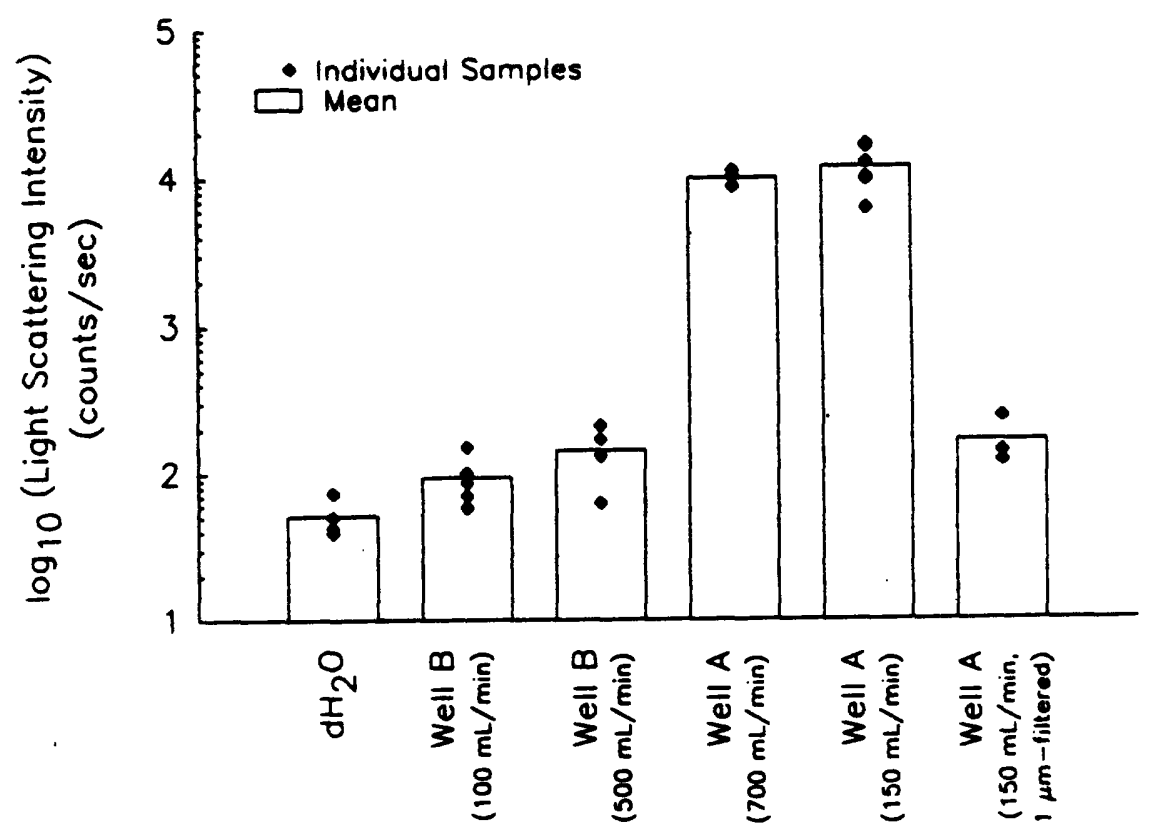

Fig. 2. Laser light scattering intensities for groundwaters collected in April 1986. Water from well $B$ is indistinguishable from the distilled water blank ( $<1 \mathrm{mg}$ colloids/L), while water from well $A$ scatters light to an extent indicative of $10-100 \mathrm{mg}$ colloids/L. Filtering with a $1-\mu \mathrm{m}$ Nuclepore filter removes much of the scattering material. 
sampled at both moderate $\left(500-700 \mathrm{~mL} \mathrm{~min}^{-1}\right)$ and low $\left(100-150 \mathrm{~mL} \mathrm{~min}^{-1}\right)$ pumping rates. Increased rates did not cause more colloids to "appear" in water from well $B$, nor did lower flow rates reduce light scattering by particles in groundwater from well $A$. Notably, filtration of water from well $A$ using a $1-\mu \mathrm{m}$ Nuclepore filter removed much of the colloidal material from this sample; thus to the extent the slow-flow samples truly reflect colloids suspended in situ, we believe this exercise shows that sample filtration biases subsequent efforts to quantify mobile species by removing colloids. Based on our experience with standard polystyrene bead scatterers, the groundwater from well $B$ contained $<1 \mathrm{mg}$ colloids/L while that from well $A$ exhibited between 10 and $100 \mathrm{mg}$ colloids/L.

\section{Laser light scattering (LLS) observations of colloids}

Results from samples taken in August confirmed and extended these LLS observations (Table 1). First, wells $A$ and $B$ yielded samples which scattered light to the same extent as observed in April samples. It is worth noting that the high-volume interceptor well located near $A$ ( $\sim 40 \mathrm{~m}$ away) was operating at the time of our sampling in April 1986, but was turned off in August 1987. Thus, it appears that enhanced groundwater flows caused by this interceptor well are not solely responsible for the presence of suspended colloids at well $A$. Additionally, we collected samples at two additional wells, $C$ and $D$ located west and southeast of the ash impacted area, respectively. Although well $C$ is located downgradient of some waste water disposal ponds, there is no evidence that groundwater there has been affected by infitrating process waters (Fig. 1). Water from well $C$ scattered light to an extent indistinguishable from distilled water. On the other hand, water from well $D$ had substantial colloidal light scattering.

To help characterize the colloids in these groundwater samples, we examined scattering intensities after various treatments (Table 1). First, we allowed the samples to stand undisturbed in the LLS instrument for a period

\section{TABLE 1}

Laser light scattering (LLS) results (in counts per second) for groundwater collected in August 1987 - Also shown are the scattering intensities for samples: (a) allowed to stand $30 \mathrm{~min}$ in the cuvette (corresponding to enough time to settle $3-\mu \mathrm{m}$ particles), and (b) acidified with $\mathrm{HCl}$ to dissolve colloidal carbonates

\begin{tabular}{lrrrr}
\hline Property & Well & & & \\
\cline { 2 - 5 } & \multicolumn{1}{c}{$B$} & \multicolumn{1}{c}{$C$} & \multicolumn{1}{c}{ C } \\
\hline LLS (cps) & 93 & 74 & 14,000 & 8,600 \\
LLS after standing 30 min & 170 & 87 & 5,300 & 6,100 \\
LLS after acidification & 143 & 490 & 3,000 & 3,100 \\
\hline
\end{tabular}


of $30 \mathrm{~min}$. Based on Stokes settling law, we anticipated that particles with hydrodynamic diameter of $\gtrsim 3 \mu \mathrm{m}$ (assuming density of $2.6 \mathrm{~g} \mathrm{~cm}^{-3}$ ) would fall below the illuminated level in the cuvette during this interval. Not surprising$l y$, the samples from wells $C$ and $B$ continued to yield background levels of scattering intensity. The colloid suspensions from wells $A$ and $D$ diminished in scattering intensity, although arguably insignificantly given the analytical variability of the measurement (e.g., see precision exhibited by replicates shown in Fig. 2). Thus, it appears these colloid suspensions were stable with respect to settling and to coagulation (which over the period of several days since sample collection could have formed faster sinking aggregates). Although we were unable to size colloids using their hydrodynamic diffusivity behavior, this settling result suggests they are predominantly $<3 \mu \mathrm{m}$. We also acidified the samples to $\mathrm{pH} 2$ by addition of a small volume of $\mathrm{HCl}$ to ascertain whether the light scattering colloids were acid-labile materials. Both samples from wells $A$ and $D$ showed decreased light scattering, and the result for groundwater from $\boldsymbol{A}$ appears outside statistical variation. We interpret this observation to mean that some subfraction of the colloids was readily dissolved in acid (e.g., carbonate solids). However, a substantial portion of the colloids from wells $A$ and $D$ was resistant to acid (e.g., silicates).

SEM examination of the colloids collected on filters during the Aùgust 1987 sampling furthers our knowledge of these microparticles. Fig. 3 shows a filter used as a field blank (i.e. loaded in the field and having $5 \mathrm{~mL}$ of distilled water forced through it). Although some particles can be seen, the filter is generally lightly covered to clear. Interestingly, a few glassy spheres, possibly fly ash particles based on their similar appearance to those reported previously by Lichtman and Mroczkowski (1985), were observed in this blank. Such spheres were not seen on any filters through which groundwater was passed.

The low coverage of blank filters strongly contrasted the SEM observations of filters from wells $A$ (Fig. 3) and $D$ whose loadings corroborate the LLS results. Interestingly, even filters from wells $B$ and $C$ show colloids clearly in excess of the field blank filter, but much less than that seen from wells $A$ and $D$. (We should note that non-detection of colloids by LLS does not mean they are absent, but rather they occur below some threshold level which is a strong function of particle size, composition and shape.) Some particles between 1 and $10 \mu \mathrm{m}$ in size can be seen on the filters, consistent with our filtering (Fig. 2) and settling (Table 1) observations. Higher magnifications of the colloids from well $A$ (Fig. 3) show particles ranging in size down to $\sim 0.1 \mu \mathrm{m}$. Many of these microparticles are "rhomboid" and sometimes appear eroded. Such colloids were not found on the field blank filters. SEM-EDAX analyses of these particles always shows the presence of $\mathrm{Si}$ and variable amounts (including none) of $\mathrm{Ca}$ and $\mathrm{Mg}$. In some instances, $\mathrm{Al}$ was also indicated. These results are consistent with our information on the soil composition indicating quartz $(\mathrm{Si})$, calcite $(\mathrm{Ca}$ and $\mathrm{Ca} / \mathrm{Mg})$, dolomite $(\mathrm{Ca}, \mathrm{Mg})$, and clays $(\mathrm{Si}, \mathrm{Al})$ are present in the area. 


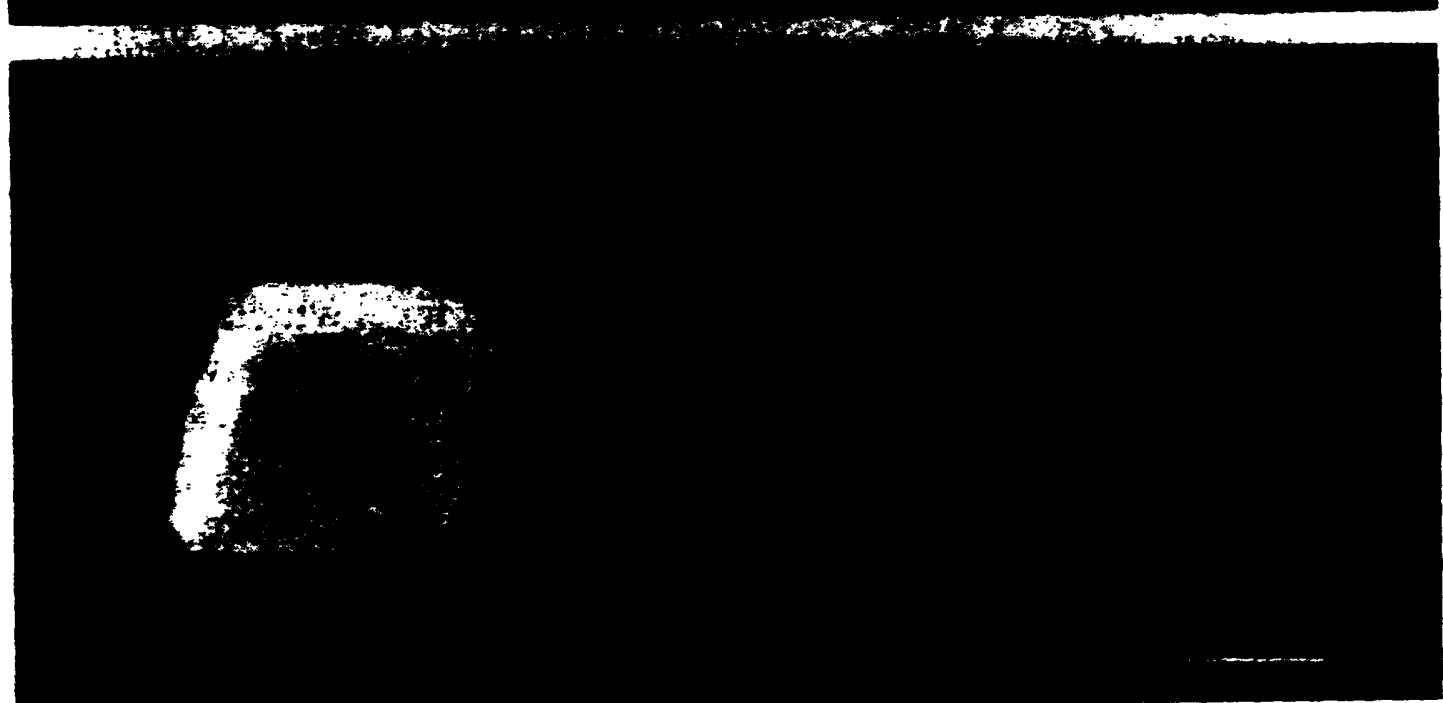

Fig. 3. Scanning electron micrographs of colloids collected on $0.03-\mu \mathrm{m}$ Nuclepore ${ }^{\oplus}$ filters: (a) field blank with arrow indicating probable fly ash particles (scale bar $=10 \mu \mathrm{m}$ ); (b) groundwater colloids from well $A$ (scale bar $=10 \mu \mathrm{m})$; and (c) rhomboid colloids from $\sim 0.1$ to $2 \mu \mathrm{m}$ from well $A$ (scale bar $=1 \mu \mathrm{m})$. 
Water chemistry and implications to colloid presence

Observations of the groundwater composition also provided important insights regarding the likely composition of the suspended colloids and the nature of their source. Data from April 1986 are shown in Table 2. Groundwater from well $A$, which exhibited large quantities of colloids relative to that from well $B$, also had much greater concentrations of major ions (e.g., conductivities or calculated ionic strengths). Another important distinction was that the wells with more colloids also showed a significantly lower $\mathrm{pH}$ (7.1 vs. 7.6 ) and a somewhat greater alkalinity (2.7 vs. $2.2 \mathrm{mM})$. This implies that the $p_{\mathrm{CO}_{2}}$ in groundwater at well $A$ was substantially greater $\left(\sim 10^{-2.0} \mathrm{~atm}\right)$ than that from well $B\left(\sim 10^{-2.6} \mathrm{~atm}\right)$. (Note: the $\mathrm{pH}$ data acquired upon returning the samples to the laboratory would be biased upwards by $\mathrm{CO}_{2}$ degassing.)

Using these water chemistry data in the chemical equilibrium model, MINEQL (Westall et al., 1976), we find that the water from well $A$ is oversaturated with respect to calcite. Since measurements of $\mathrm{Ca}^{2+}$ concentration and alkalinity are not particularly prone to error, we considered that solution $\mathrm{pH}$, assessed in the field to $\sim \pm 0.1 \mathrm{pH}$ unit, would be weakest input to these equilibrium calculations. However, as illustrated in Fig. 4, the $\mathrm{pH}$ measured at well $A$ was clearly above that necessary to conclude that the $\mathrm{Ca}$ and total inorganic carbon measured reflected a supersaturation condition. The result at site $A$ is

TABLE 2

Water chemistry data for groundwater samples in April 1986

\begin{tabular}{|c|c|c|c|c|}
\hline \multirow[t]{2}{*}{ Parameter } & \multicolumn{2}{|c|}{$\begin{array}{l}\text { Groundwater with low } \\
\text { colloid concentrations }\end{array}$} & \multicolumn{2}{|c|}{$\begin{array}{l}\text { Groundwater with high } \\
\text { colloid concentrations }\end{array}$} \\
\hline & well $B^{\star 1}$ & well $B^{\star 2}$ & well $A^{\star 1}$ & well $A^{\star 2}$ \\
\hline Conductivity $\left(\mathrm{mS} \mathrm{cm}^{-1}\right)$ & 1.08 & 1.14 & 4.00 & 3.07 \\
\hline pH & 7.6 & 7.9 & 7.1 & $7.8^{\star 3}$ \\
\hline$E_{\mathrm{H}}(\mathrm{mV})$ & +100 & - & +100 & - \\
\hline $\mathrm{Na}^{+}(\mathbf{m M})$ & 4.8 & 5.0 & 24.8 & 16.5 \\
\hline $\mathrm{K}^{+}(\mathbf{m} M)$ & - & 0.12 & - & 0.43 \\
\hline $\mathrm{Ca}^{2+}(\mathrm{mM})$ & 2.2 & 2.2 & 11.2 & 5.2 \\
\hline $\mathrm{Mg}^{2+}(\mathrm{mM})$ & 1.4 & 1.3 & 7.0 & 2.9 \\
\hline $\mathrm{Cl}^{-}(\mathbf{m M})$ & 3.1 & 3.6 & 17.5 & 11.6 \\
\hline $\mathrm{HCO}_{3}^{-}(\mathbf{m} M)$ & 2.2 & 2.2 & 2.7 & 2.2 \\
\hline $\mathrm{SO}_{4}^{2-}(\mathrm{mM})$ & 3.4 & 2.8 & 20.8 & 10.9 \\
\hline Calculated ionic strength $(M)$ & 0.02 & 0.02 & 0.1 & 0.05 \\
\hline Calculated $p_{\mathrm{CO}_{2}}$ (atm) & $10^{-2.6}$ & $10^{-29}$ & $10^{-20}$ & $10^{-28}$ \\
\hline
\end{tabular}

$-=$ not determined.

*1 Sample was stored in glass DO bottles and not filtered before analysis.

${ }^{\star 2}$ Sample was stored in sealed plastic containers and filtered through $0.45-\mu \mathrm{m}$ Millipore ${ }^{\bullet} \mathrm{mem}$ branes before analysis.

*3 Measured after returning to the laboratory. 


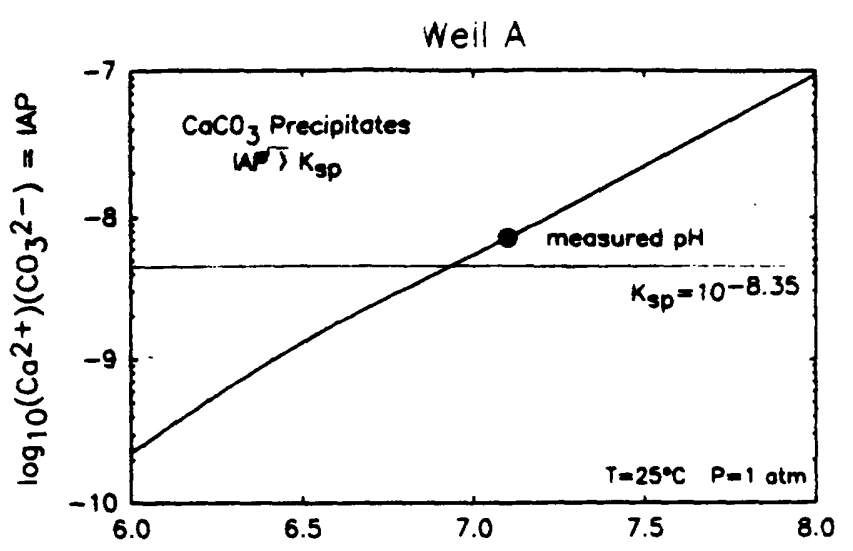

Well B

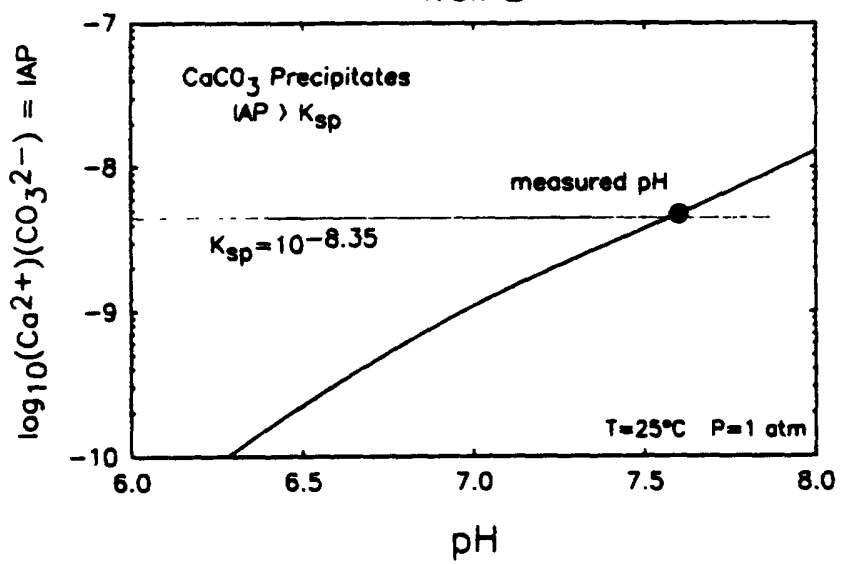

Fig. 4. Comparison of computed ion activity products with the calcite solubility product showing the apparent supersaturation for our measured $\mathrm{pH}$ at well $A$, but the equilibrium situation for our measured $\mathrm{pH}$ at well $B$. Computations for well $A$ based on an ionic strength of $0.1 M$, $\gamma_{\mathrm{C}_{2}}=\gamma_{\mathrm{CO}_{2}} \approx 0.4, K_{\mathrm{a}_{1}}=10^{-6.2}, K_{\mathrm{z}_{2}}=10^{-9.9}, \mathrm{Ca}_{\mathrm{T}}=1.1 \cdot 10^{-2} M$, and $C_{\mathrm{T}}=2.7 \cdot 10^{-3} M$; while those for well. $B$ use lonic strength of $0.02 M, \gamma_{c_{n}}=\gamma_{c_{3}} \approx 0.6, K_{a_{1}}=10^{-6.3}, K_{a_{2}}=10^{-10.1}$, $\mathrm{Ca}_{\mathrm{T}}=2.2 \cdot 10^{-3} \mathrm{M}$, and $C_{\mathrm{T}}=2.2 \cdot 10^{-3} \mathrm{M}$.

unlikely to reflect in situ supersaturation as much as it indicates that carbonate colloids were included in the unfiltered water which we measured for $\mathrm{Ca}^{2+}$ and $\mathrm{HCO}_{3}^{-}$. The difference in results with and without filtering corresponds to $50 \mathrm{mg} \mathrm{CaCO}$ colloids/L. This result is consistent with the range of $10-100 \mathrm{mg}$ colloids/L derived from the LLS intensity.

On the other hand, the MINEQL calculations using the water chemistry of well $B$ suggest this groundwater is just saturated with respect to calcite. As demonstrated in Fig. 4, the measured pH at this well is indistinguishable from that necessary for saturation. These findings are consistent with the greatly diminished concentrations of colloids in this well water and with the correspondence of alkalinity results between filtered and unfiltered samples (Table 2).

Finally, we note that the MINEQL calculations indicate groundwaters from either well $A$ or well $B$ are well undersaturated with respect to gypsum $\left(\mathrm{CaSO}_{4} \cdot 2 \mathrm{H}_{2} \mathrm{O}\right)$, wollastonite $\left(\mathrm{CaSiO}_{3}\right)$ and diopside $\left(\mathrm{CaMgSi}_{2} \mathrm{O}_{6}\right)$, if we apply our observed sulfate data and the dissolved silicic acid concentrations reported 
by others ( $0.5 \mathrm{~m} M$ at $A$ and $0.4 \mathrm{~m} M$ at $B)$. These silicic acid levels also indicate that the groundwater is supersaturated with respect of quartz $(\sim 0.1 \mathrm{mM}$; Wollast, 1974) and undersaturated with respect to amorphous silica ( $2 \mathrm{mM}$; Wollast, 1974). As noted by Siever (1957), precipitation of quartz from water at temperatures near $25^{\circ} \mathrm{C}$ occurs exceedingly slowly, if ever. Various aluminosilicate clays (e.g., montmorillonite) are known to be equilibrated with $\sim 0.1-$ $0.5 \mathrm{mM}$ silicic acid solutions (Mackenzie et al., 1967; Iler, 1979). Thus, it appears that calcite and possibly clays are the thermodynamically stable solids in this groundwater system. These mineral stability considerations correspond well with the observed elemental compositions we found using SEM-EDAX on the colloids recovered by filtering at the site.

In August 1987, we re-examined the groundwater chemistry to further discern differences between wells with colloids $(A$ and $D)$ vs. those without $(B$ and $C$ ). Once again groundwaters with large light scattering loads (from wells $A$ and $D$ ) revealed alkalinity changes of $0.2-0.3 \mathrm{mM}$ after measures to remove colloids (Table 3), indicating a carbonate fraction of $\sim 20-30 \mathrm{mg} \mathrm{L}^{-1}$ in the colloids. Also as shown in Table 3, the key parameters distinguishing groundwaters with colloids were relatively low pH (especially $A$ ) and low dissolved oxygen (both wells $A$ and $D$ ). These results reaffirm the previous observation of elevated $p_{\mathrm{CO}_{2}}$ at sites with colloids. $p_{\mathrm{CO}_{2}} \cdot$ Values near $10^{-2}$ atm are not unusual in deep soil horizons (Stumm and Morgan, 1981), and Wood and Petraitis (1984) have shown that such high concentrations can even be found $20-30 \mathrm{~m}$ below the ground surface in the semi-arid region of southern Texas, U.S.A. The depleted oxygen levels in groundwaters of our study indicate at least some of the excess $\mathrm{CO}_{2}$ derives from oxidation of organic matter. Although it would seem that not

TABLE 3

Groundwater chemistry for samples collected at an electric generating station in August 1987

\begin{tabular}{|c|c|c|c|c|}
\hline \multirow[t]{2}{*}{ Parameter } & \multicolumn{2}{|c|}{$\begin{array}{l}\text { Wells exhibiting low } \\
\text { levels of colloids }\end{array}$} & \multicolumn{2}{|c|}{$\begin{array}{l}\text { Wells exhibiting high } \\
\text { levels of colloids }\end{array}$} \\
\hline & well $B$ & well $C$ & well $A$ & well $D$ \\
\hline Conductivity (mS cm $\left.{ }^{-1}\right)$ & 1.6 & 1.4 & 7.4 & 1.8 \\
\hline pH & 7.1 & 7.2 & 6.8 & 7.1 \\
\hline Alkalinity (mM) & 2.3 & 2.4 & 3.4 & 2.4 \\
\hline $\begin{array}{l}\text { Alkalinity after } \\
\text { centrifugation }{ }^{\star 1}(\mathrm{mM})\end{array}$ & 2.4 & 2.4 & 3.1 & 2.2 \\
\hline$E_{\mathrm{H}}(\mathrm{mV})$ & +60 & +90 & +60 & +60 \\
\hline Dissolved oxygen ( $\mu M$ ) & 170 & 170 & 100 & 40 \\
\hline Calculated $\mathrm{p}_{\mathrm{CO}_{2}}{ }^{\star 2}$ (atm) & $10^{-1.9}$ & $10^{-2.0}$ & $10^{-1.5}$ & $10^{-2.0}$ \\
\hline
\end{tabular}

-l Centrifugation at $2000 \mathrm{~g}$ for $30 \mathrm{~min}$.

${ }^{\star 2} \mathrm{PCO}_{2} \approx(\mathrm{alk})\left(\mathrm{H}^{+}\right) \mathrm{K}_{\mathrm{H}}{ }^{-1} \mathrm{~K}_{\mathrm{a}_{1}}{ }^{-1}$. 
much labile organic matter would be oxidized in the subsurface at such a semi-arid site, Wood and Petraitis (1984) have provided strong evidence, using carbon isotopes in $\mathrm{CO}_{2}$ of the deep Texas soil, that the elevated $\mathrm{p}_{\mathrm{CO}_{2}}$ arises from organic matter oxidation occurring at all depths of the vadose zone.

Hypothesized scenario explaining colloids in groundwater near an ash disposal site

In light of these colloid and water chemistry observations, we advance the following hypothesis to explain the origin of these suspended microparticles (Fig. 5). When runoff infiltrates the ash impacted areas, supersaturation with respect to calcite is alleviated by precipitating carbonate solids from a solution in near equilibrium with atmospheric $\mathrm{CO}_{2}$ (i.e. $p_{\mathrm{CO}_{2}} \sim 10^{-3.5} \mathrm{~atm}$ ). As the water infiltrates, organic matter in the water or from the soil is oxidized by soil microorganisms yielding increasing amounts of $\mathrm{CO}_{2}$ in the soil atmosphere. This carbon dissolves in the soil water and causes the dissolution of carbonate solids in the soil. Wood and Petraitis (1984) proposed that the development of secondary porosity observed in the vadose zone above the Ogallala aquifer in southern Texas was due to such $\mathrm{CO}_{2}$-driven calcite dissolution. In the predominantly quartzite sands of the aquifer at our site, this calcite (and dolomite) dissolution amounts to decementation of the sandy soil (Pettijohn et al., 1987). As a result, infiltrating waters may carry newly mobilized colloidal silicates (with residual carbonate cement as indicated by the SEM-EDAX) to the water table where they are free to move with the flowing groundwater. This process may operate at this site because: (1) very large volumes of water infiltrate through fairly narrow areas to the water table; (2) the water has high ionic strengths lowering ion activity coefficients; (3) the infiltrating fluids include anions such as $\mathrm{SO}_{4}^{2-}$ that effectively complex dissolved $\mathrm{Ca}^{2+}$ and $\mathrm{Mg}^{2+}$; (4) the

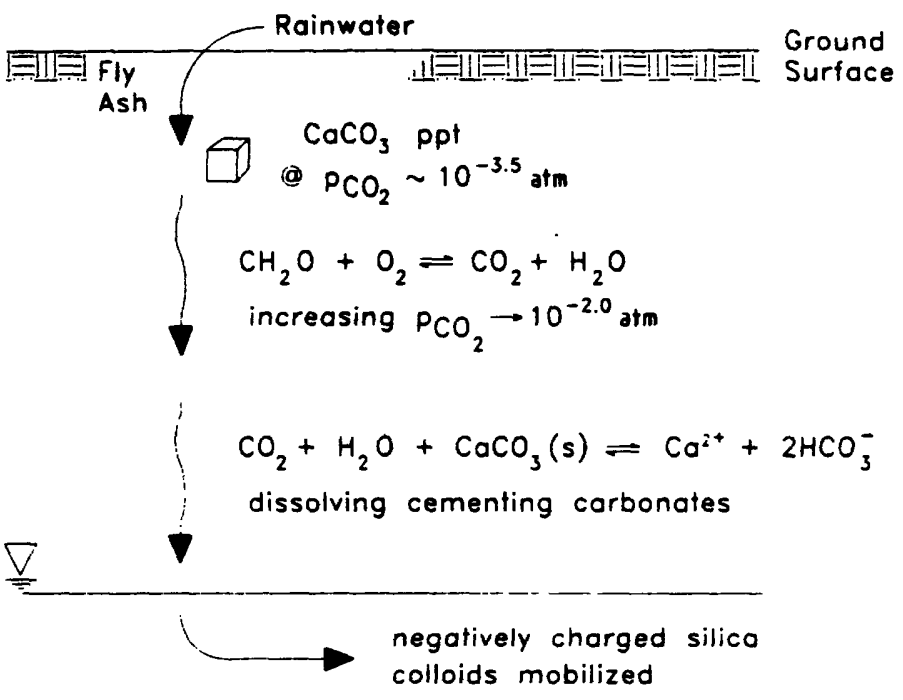

Fig. 5. Hypothesized sequence of events causing the mobilization of colloids in groundwater near ash disposal site. 
soil atmosphere builds up $\mathrm{CO}_{2}$ levels sufficient to drive substantial carbonate dissolution; and (5) the primarily quartz soil is cemented only "lightly" (e.g., $\sim 5 \%$ calcite in a soil core collected near well $A$ ). Since the mobilized silicate colloids would be negatively charged at the near-neutral $\mathrm{pH}$ of the groundwater, their propensity to be filtered by the immobile quartz surfaces of the aquifer would be minimal.

\section{SUMMARY AND CONCLUSIONS}

Our results indicate that colloidal particles are suspended in some groundwaters collected in this study. This conclusion is supported by several points: (1) we continue to see these colloids even using extremely careful sampling procedures; (2) we do not see such quantities of colloids in neighboring wells screened in the same geologic formation and installed and developed in the same manner; (3) the colloid size and surface chemistry appear suitable to provide for their stabilization once they have been mobilized; and (4) the groundwater chemistry at wells exhibiting colloids is distinct from those without these microparticles and suggests a plausible mechanism for their mobilization. Thus, we strongly suspect that colloids contribute to the mobile load in groundwater beneath some portions of the electric generating station.

The presence of these colloids certainly affects the chemicals measured and presumably transported in these groundwaters. First, we have seen colloids in wells $A$ and $D$ contribute $\sim 0.2-0.5 \mathrm{mM}$ to the carbonate alkalinity. Additionally, this carbonate colloid fraction could contribute a few percent to measured $\mathrm{Ca}^{2+}$ or $\mathrm{Mg}^{2+}$. Obviously, silicic acid measurements could also be affected by the presence of the colloids. In related work, we find several trace elements are detectable in solids filtered from groundwater from this site. Thus, pollutants likely to sorb to silicate colloids (e.g., trace metal cations) or to be included in colloidal carbonates (e.g., Sr and Cd; Davis et al., 1987; Fuller and Davis, 1987) may be particularly susceptible to facilitated transport by these mobilized colloids.

Interestingly, we have seen no evidence (e.g., glassy spheres not seen by SEM) for fly ash particles being carried to the groundwater. Wood and Petraitis (1984) speculated that submicrometer smectite particles from zones near the ground surface may transport labile organic matter to the deep soils above the Ogallala aquifer, especially as continued dissolution of the calcareous cement there provided increasingly important secondary porosity. Such an effect may also eventually become important near the studied site.

Future estimates of contaminant transport from the site should include consideration of colloid-associated movement. This case appears to illustrate a phenomenon likely to occur widely: that is, wherever the groundwater geochemistry has been "adjusted" by the activities of man to cause decementation (e.g., loss of carbonate or other phases like Fe-oxides which are important to other regions), soil colloids may be mobilized. If the solution and surface chemistries are suitable, these microparticles may be poorly filtered as they are 
carried through the porous medium, and thereby they may contribute to the subsurface transport of sorbed pollutants.

\section{ACKNOWLEDGMENTS}

We would like to acknowledge the financial support of a consortium of energy companies including Southern California Edison, Northeast Utilities Service Company, Empire State Electric Energy Research Corporation, BP America, New England Power Service Company and American Electric Power Service Corporation. Ed Selig performed our SEM analyses, and Louie Kerr helped us with the SEM-EDAX studies. Joe Ryan carried out the X-ray diffraction tests on our soil samples.

\section{REFERENCES}

Backhus, D.A., Geschwend, P.M. and Reynolds, M.D., 1986. Sampling colloids in groundwater. Eos (Trans. Am. Geophys. Union), 67: 954 (abstract).

Buddemeier, R.W. and Hunt, J.R., 1988. Transport of colloidal contaminants in groundwater: radionuclide migration at the Nevada Test Site. Appl. Geochem., 3: 535-548.

Champ, D.R., Young, J.L., Robertson, D.E. and Abel, K.H., 1984. Chemical speciation of long-lived radionuclides in a shallow groundwater flow system. Water Pollut. Res. J. Can., 19: 35-54.

Davis, J.A., Fuller, C.C. and Cook, A.D., 1987. A model for trace metal sorption processes at the calcite surface: Adsorption of $\mathrm{Cd}^{2+}$ and subsequent solid solution formation. Geochim. Coemochim. Acta, 51: 1477-1490.

Enfield, C.G. and Bengtseon, G., 1988. Macromolecular transport of hydrophobic contaminants in aquatic environments. Ground Water, 26: 64-70.

Fuller, C.C. and Davis, J.A., 1987. Processes and kinetics of $\mathrm{Cd}^{2+}$ sorption by a calcareous aquifer sand. Geochim. Cosmochim. Acta, 51: 1491-1502.

Gschwend, P.M. and Reynolds, M.D., 1987. Monodisperse ferrous phosphate colloids in an anoxic groundwater plume. J. Contam. Hydrol., 1: 309-327.

Iler, R.K., 1979. The Chemistry of Silica. Wiley-Interscience, New York, NY, 866 pp.

Lichtman, D. and Mroczkowski, S., 1985. Scanning electron microscopy and energy-dispersive X-ray spectroscopy analysis of submicrometer coal fly ash particles. Environ. Sci. Technol., 19: 274-277.

Mackenzie, F.T., Garrels, R.M., Bricker, O.P. and Bickley, F., 1967. Silica in sea water: Control by silica minerals. Science, 155: 1404-1405.

McDowell-Boyer, L.M., Hunt, J.R. and Sitar, N., 1986. Particle transport through porous media. Water Resour. Res., 22: 1901-1921.

Pettijohn, F.J., Potter, P.E. and Siever, R., 1987. Sand and Sandstone. Springer, New York, NY, 2nd ed., 553 pp.

Ryan, J.N., 1988. Groundwater colloids in two Atlantic Coastal Plain aquifers: Colloid formation and stability. M.S. Thesis, Department of Civil Engineering, Massachusetts Institute of Technology, Cambridge, MA, $250 \mathrm{pp}$.

Siever, R., 1967. The silica budget in the sedimentary cycle. Am. Mineral., B: 821-841.

Stumm, W. and Morgan, J.J., 1981. Aquatic Chemistry. Wiley-Interscience, New York, NY, 2nd ed., 780 pp. (see especially pp. 534-538).

Westall, J.C., Zachary, J.L. and Morel, F.M.M., 1976. MINEQL - A computer program for calculation of chemical equilibrium composition of aqueous systems. R.M. Parsons Lab., Mass. Inst. Technol., Cambridge, MA, Tech. Note No. 18.

Wollast, R., 1974. The silica problem. In: E.D. Goldberg (Editor), The Sea, Vol. 5. Wiley-Interscience, New York, NY, pp. 359-392.

Wood, W.W. and Petraitis, M.H., 1984. Origin and distribution of carbon dioxide in the unsaturated zone of the southern high plains of Texas. Water Resour. Res., 20: 1193-1208. 